\title{
Job satisfaction of senior staff nurses in selected Upazila health complexes
}

\author{
Abdul Karim ${ }^{1, *}$ and Priti Lata Mondal ${ }^{2}$ \\ ${ }^{1}$ College of Nursing, Sher-E-Bangla Nagar, Dhaka, Bangladesh. \\ ${ }^{2}$ National Institute of Diseases of the Chest and Hospital, Dhaka, Bangladesh.
}

International Journal of Biological and Pharmaceutical Sciences Archive, 2021, 02(01), 072-083

Publication history: Received on 17 June 2021; revised on 30 July 2021; accepted on 02 August 2021

Article DOI: https://doi.org/10.53771/ijbpsa.2021.2.1.0065

\begin{abstract}
A descriptive type of cross-sectional study was conducted with the objective to determine the status of job satisfaction of senior staff nurses working at Upazila Health Complex. A total of 152 senior staff nurses were selected purposively from 16 upazila health complex where data collection instrument was self- administered semi-structured questionnaire. Results revealed that the mean age of the respondents was $44.05 \pm 7.01$ years. In education, majority of the respondents $(72.4 \%, n=110)$ were diploma in nursing and $20.4 \%(n=31)$ BSc in nursing. Among them, 30.9\% (n=47) respondents had monthly income from Tk. 21000-25000. Majority of the respondents $(61.8 \%$, n=94) had permanent job and $23.7 \%(n=36)$ respondents had temporary job. Majority of the respondents $(60.6 \%, n=92)$ were working as senior stuff nurse for above eight years. Majority of the respondents $(73.7 \%, n=112)$ had working experience above four years. Most of the respondents $(86.2 \%, n=131)$ had national training. $36.8 \%(n=56)$ respondents were satisfied with the salary they got. Few of the respondents $(8.6 \%, n=13)$ were satisfied with the working environment. $23.0 \%$ $(n=35)$ respondents were dissatisfied with the freedom to choose own work. $22.4 \%(n=34)$ respondents were satisfied with recognition of performance at work. Most of the respondents $(86.2 \%, n=131)$ respondents were neither satisfactory nor dissatisfactory with cooperation from superior. $18.4 \%(n=28)$ respondents were satisfied with relation with colleague. $28.9 \%(n=44)$ respondents were dissatisfied with job security. Majority of the respondents $(64.8 \%$, $\mathrm{n}=104$ ) were neither satisfactory nor dissatisfactory with fringe benefit from service. Majority of the respondents $(57.9 \%, n=88)$ respondents were dissatisfied with promotional scope. $39.5 \%(n=60)$ respondents were satisfied with the place of posting.16.4\% ( $\mathrm{n}=25)$ respondents were dissatisfied with opportunity for career advancement. Majority of the respondents $(72.4 \%, n=110)$ were satisfied with their jobs. $17.8 \%(n=27)$ respondents had poor satisfaction level regarding their jobs. Majority of the respondents $(51.3 \%, \mathrm{n}=78)$ said that political influence affect their job satisfaction. $13.2 \%(n=20)$ respondents said that communication barrier affect their job satisfaction. Respondent's age ( $p=0.004)$, educational status $(p=0.030)$ and monthly family income $(p=0.052)$ was significantly associated with level of job satisfaction. Special attention should be given for their promotional opportunity to increase their level of job satisfaction.
\end{abstract}

Keywords: Job satisfaction; Nurses; Upazila Health Complexes; Bangladesh

\section{Introduction}

Job satisfaction is defined as the perceived relationship between what one expects and obtains from one's job and how much importance or value is attributed to the job [1]. It represents the degree to which employees enjoy their jobs, an important aspect for both the employees and their organizations. Job satisfaction is one of the important variables in work and organizational psychology, is regarded as an indicator of working - life quality [2]. Job satisfaction has been described as an attitude with an affective and cognitive component [3]. Health sector is labor intensive where service quality and efficiency are directly influenced by workers satisfaction, motivation and health worker's willingness to

\footnotetext{
* Corresponding author: Abdul Karim

College of Nursing, Sher-E-Bangla Nagar, Dhaka, Bangladesh.
}

Copyright (C) 2021 Author(s) retain the copyright of this article. This article is published under the terms of the Creative Commons Attribution Liscense 4.0. 
apply resources to the task at work place [4]. In recent years, there has been increased scholarly attention on the job satisfaction of nurses because of the need to improve the quality of care, health outcomes and the performance of the health system [5]. A high correlation has been found between nurse's performance and their job satisfaction [6] while dissatisfaction can be costly and disruptive to organizational effectiveness [7].

Nowadays the public views towards nursing and midwifery profession have gradually improving, however, nursing was not considered as a respectable profession in Bangladesh. Nurses were not expected to enjoy any prestigious image and privileged reputations in the society for several reasons such as socio-cultural attitude, the type of work, inadequate financial rewards or salaries, low status of women dominated by other professionals [8]. The unimpressive societal image, family disagreement, cultural and communal values, working hours including night duty, scope of mixing with members of the opposite gender, and the worry of not being a "marriageable" prospect where the main reasons why females did not choose nursing as a career in the past [8]. Problems were also associated with inadequate performance of the nurse-midwives related to insufficient education and training along with a lack of professionalism [9]. "Nursing Experts" believe that the status of nursing in the society has recently been viewed as an important and valuable profession. To upgrade the social image towards nursing, the present government has taken several initiatives including the start of generic B. Sc nursing course in both public and private sectors with upgraded students' entry requirement, providing opportunities for higher education both nationally and internationally, upgrading the diploma nurses' position from Class-III to Class-II status, and expansion of nursing educational institutions all over the country. In addition, the active involvement of nurses-midwives in different national health care issues (EPI, disaster management, maternal and child health) and having the opportunity to work abroad in the Middle-East, Canada, UK, USA, Italy has given a brighter image to the nursing profession and has increased the public interest towards the profession. A group of medical students in the capital city expressed their opinion on nursing profession as follows: - nursing is a noble, respected, and humanitarian profession. Nurses' social status should be high as they are very helpful for diseased people and not less importance than medical doctors. They are an enlightened workforce of the country serving the needs of humanity.

Nurses play an integral and crucial role in any health care organization. Unfortunately, nurses may experience low levels of job satisfaction, an important factor that influences nurses' clinical performance [10]. Job performance is positively correlated with job satisfaction and other factors. Job satisfaction is a vital outcome to any health care organization as it is an indicator of the status of its employees. Hence, it is important for administrators to understand the foundation of job satisfaction because of the serious impact that dissatisfaction can have in the workplace. In nursing, most of the published studies examine job satisfaction as a key indicator of nurses' performance, cost savings, and quality of patient care [11]. With the decrease of nurse job satisfaction, the qualities of nursing care would be affected leading to the increase in the mortality rate of patients [12].

There is a lack of trained nurses in Bangladesh and their salary is not satisfactory. For this reason, they are socially underestimated for their profession and nursing is not getting its due recognition. Nurses are somehow neglected but their need is of great importance. The aim of the proposed study is to assess the job satisfaction of senior staff nurses working at Upazila Health Complex, This study will provide valuable information about job satisfaction of senior staff nurses of Upazila Health Complexes which can be an important source of information for the policy makers in health sectors to assess the field that need future improvement, which in turn will lead to an efficient health care providing system and improve the quality of services and also benefit to the quality of life of the population of Bangladesh.

\subsection{Research Question}

What is the level of job satisfaction of senior staff nurses working at Upazila Health Complex?

\subsection{Objectives of the study}

\subsubsection{General objective}

To determine the level of job satisfaction of senior staff nurses working at Upazila Health Complex.

\subsubsection{Specific objectives}

- To assess the job-related personal attributes of senior staff nurses in Upazila Health Complex

- To assess the level of job satisfaction of the senior staff nurses

- To identify the organizational influences on job satisfaction

- To identify the socio-demographic characteristics of the respondents. 


\section{Material and methods}

\subsection{Study Type}

The study is a descriptive type of cross-sectional study. Data were collected from respondents once only.

\subsection{Study Population}

Study population was senior staff nurses of 16 Upazilla Health Complexs of five districts of Barisal Division.

\subsection{Study Place}

The study was carried out in16 Upazila Health Complexes in Barisal division which are mentioned below-

\subsubsection{Name of five District}

Patuakhali, Borguna, Pirojpur, Jhalohathi and Barisal.

\subsubsection{Name of Upazila Health Complex (UHC)}

UHC, Bauphal; UHC, Dasmina; UHC, Dumki; UHC, Mirzajong; UHC, Amtoli; UHC, Bamna; UHC, Betagi; UHC, Pathorghata; UHC, Cowkhali; UHC, Motbaria; UHC, Swarupkathi; UHC, Vanderia; UHC, Kathaliya; UHC, Rajapur; UHC, Banaripara and UHC, Bakerjong.

\subsection{Study Period}

The study was conducted for the one year during the period of January, 2016 to December, 2016.

\subsection{Sampling Method}

The sample was collected by purposive sampling technique who fulfill the selection criteria.

\subsubsection{Inclusion criteria}

- Senior Staff Nurses (SSN) of mentioned Upazilla Health Complexes.

- Service experience minimum one year of that Upazilla Health Complexes.

\subsubsection{Exclusion criteria}

- Respondents who were on leave or training.

- Senior Staff Nurses who were not willing to participate.

\subsection{Sample Size}

Statistically the following formula is used to calculate the sample size:

$$
\mathrm{n}=\mathrm{z}^{2} \mathrm{pq} / \mathrm{d}^{2}
$$

Where,

$\mathrm{n}=$ required sample size

$\mathrm{z}=$ level of significance

$\mathrm{p}=$ proportion in the population possessing the characteristics of interest

$\mathrm{q}=1-\mathrm{p}$

$\mathrm{d}=$ Standard error

The ' $p$ ' is the proportion of nurses who were satisfied with their jobs which was found $52.5 \%$ in Ethiopia [16].

Therefore $\mathrm{p}=0.53 \mathrm{q}=1-\mathrm{p}$ or $\mathrm{q}=1-0.55=0.47$.

A 95\% confidence interval $(\mathrm{z}=1.96)$ with 0.05 standard error $(\mathrm{d}=0.05)$ was to be desired in this study. 
Hence, the sample size was as follows:

$$
\begin{gathered}
n=\frac{1.96^{2} \times 0.53 \times 0.47}{0.05^{2}} \\
=382.78
\end{gathered}
$$

But due to time constraint, researcher was able to collect 152 data within this time frame.

\subsection{Data Collection Technique}

Data were collected by face-to-face interview. The researcher himself collected the data.

\subsection{Research Tools}

Self-administered, semi-structured questionnaire was used to collect data. A semi-structured questionnaire was developed keeping the objectives and variables to be studied in mind.

First part of the questionnaire included socio-demographic information of the respondents.

Second part of the questionnaire contained 15 questions regarding job satisfaction of the respondents. While asking satisfaction related questions, three responses were there- satisfactory, neither satisfactory nor dissatisfactory and dissatisfactory. Each answer had a numerical value $(3,2,1$ respectively) and the final score had a maximum value of 45 . The level of satisfaction was classified as bellow:

\subsubsection{Good}

If respondents were able to score $80 \%$ and above, they were considered as having good satisfaction level regarding their jobs.

\subsubsection{Satisfactory}

If respondents scored from $60 \%$ to $79 \%$, they were considered as satisfied with their jobs.

\subsubsection{Poor}

If respondents scored below $60 \%$, they were considered as having poor satisfaction level regarding their jobs.

Third part of the questionnaire contained questions regarding factors that affect the job satisfaction of the respondents.

\subsection{Statistical Analysis}

The collected data were checked and verified by the investigator at the end of every working day. Any inaccuracy and inconsistency were corrected in the next working day. The data collected from the respondents were analyzed. After completion of data collection, to maintain consistency, the data were checked and edited manually and verified before tabulation. Data were coded, entered and analyzed in a computer. The statistical analysis was conducted using SPSS (statistical package for social science) version 20 statistical software. The findings of the study were presented by frequency, percentage in tables and graphs. Means and standard deviations for continuous variables and frequency distributions for categorical variables were used to describe the characteristics of the total sample. Educational level was assessed as categorical responses.

\subsection{Ethical Implication}

- The study was approved by ethical review board of National Institute of Preventive and Social Medicine (NIPSOM).

- Before collection of data written permission was taken from the authority of those selected Upazila Health Complexes (UHC).

- Before initiation of the data collection a brief introduction on the aims and objectives of the study was given to the respondents.

- Each participant was informed about the research, assured and informed written consent was taken

- They were informed about their full right to participate or refuse to participate in the study. 
- Complete assurance was given to them that all information by them would be kept confidential and would not be used for any other purpose except research.

- Research findings and result of the study will be explained to the respondent's without any distortions.

\section{Results}

Total 152 respondents were interviewed in 16 Upazila Health Complexes. After completion of the data analysis, the results were organized in the tabular form and figures as necessary respectively. The tables and figures are described as follows:

Table 1 Distribution of the respondents according to socio-demographic variables ( $\mathrm{n}=152)$

\begin{tabular}{|c|c|c|c|}
\hline Variables & Characteristics & Frequency & Percentage \\
\hline \multirow[t]{4}{*}{ Age (in years) } & 28 to 37 & 26 & 17.1 \\
\hline & 38 to 47 & 73 & 48.0 \\
\hline & 48 to 57 & 53 & 34.9 \\
\hline & \multicolumn{3}{|l|}{ Mean \pm SD $44.05 \pm 7.01$} \\
\hline \multirow[t]{2}{*}{ Gender } & Male & 4 & 2.6 \\
\hline & Female & 148 & 97.4 \\
\hline \multirow[t]{3}{*}{ Religion } & Islam & 91 & 59.9 \\
\hline & Hindu & 57 & 37.5 \\
\hline & Christian & 4 & 2.6 \\
\hline \multirow[t]{4}{*}{ Educational qualification } & Diploma in nursing & 110 & 72.4 \\
\hline & BSc in nursing & 31 & 20.4 \\
\hline & BSc in public health nursing & 6 & 3.9 \\
\hline & Master's in Public Health. & 5 & 3.3 \\
\hline \multirow{3}{*}{$\begin{array}{l}\text { Monthly income } \\
\text { (in taka) }\end{array}$} & $15000-25000$ & 65 & 42.7 \\
\hline & $25000-35000$ & 76 & 50.0 \\
\hline & Above 35000 & 11 & 7.3 \\
\hline \multirow[t]{3}{*}{ Marital status } & Married & 133 & 90.7 \\
\hline & Unmarried & 4 & 2.6 \\
\hline & Others & 15 & 6.7 \\
\hline \multirow[t]{3}{*}{ Family member } & Two to three & 33 & 21.7 \\
\hline & Four to five & 93 & 61.2 \\
\hline & Six to seven & 26 & 17.1 \\
\hline \multirow[t]{4}{*}{ Residence } & Own house & 61 & 40.1 \\
\hline & Rented house & 45 & 29.6 \\
\hline & Dormitory & 35 & 23.0 \\
\hline & Government quarter & 11 & 7.2 \\
\hline \multirow[t]{2}{*}{ Housing structure } & Building & 117 & 77.0 \\
\hline & Semi-pacca house & 25 & 16.4 \\
\hline
\end{tabular}




\begin{tabular}{|c|c|c|c|}
\hline & Tin shed house & 10 & 6.6 \\
\hline \multirow[t]{2}{*}{ Tobacco consumption habit } & Yes & 59 & 38.8 \\
\hline & No & 93 & 61.2 \\
\hline \multirow[t]{3}{*}{ Type of jobs } & Permanent job & 94 & 61.8 \\
\hline & Temporary job & 36 & 23.7 \\
\hline & Ad hoc & 22 & 14.5 \\
\hline \multirow[t]{3}{*}{ duration of job (in years) } & Up to four & 25 & 16.4 \\
\hline & Five -eight & 35 & 23.0 \\
\hline & Above eight & 92 & 60.6 \\
\hline \multirow[t]{3}{*}{ Working experience (in years) } & Up to two & 19 & 12.5 \\
\hline & Three -four & 21 & 13.8 \\
\hline & Above four & 112 & 73.7 \\
\hline \multirow[t]{2}{*}{ National training } & Yes & 131 & 86.2 \\
\hline & No & 21 & 13.8 \\
\hline \multirow[t]{2}{*}{ International training } & Yes & 16 & 10.5 \\
\hline & No & 136 & 89.5 \\
\hline \multirow[t]{2}{*}{ Diabetes mellitus } & Yes & 16 & 10.5 \\
\hline & No & 136 & 89.5 \\
\hline \multirow[t]{2}{*}{ Hypertension } & Yes & 35 & 23.0 \\
\hline & No & 117 & 77.0 \\
\hline
\end{tabular}

Table 1 shows the distribution of the respondents according to socio-demographic variables. The mean age of the respondents was $44.05 \pm 7.01$ years. Among them, $17.1 \%$ respondents were from 28 to 37 years age group, $48.0 \%$ respondents were from 38 to 47 years age group and $34.9 \%$ respondents were from 48 to 57 years age group. Among the respondents, 97.4\% ( $n=148)$ respondents were female and $2.6 \%(n=4)$ respondents were male. Most of the respondents $(n=91,59.9 \%)$ were Muslims. $37.5 \%$ respondents $(n=57)$ were Hindus and $2.6 \%$ respondents $(n=4)$ were Christian. Highest $72.4 \%(n=110)$ respondents were diploma in nursing and $20.4 \%(n=31)$ respondents were BSc in nursing, 3, $9 \%(n=6)$ BSc in public health nursing and 3, 3\% $(n=5)$ were Masters in Public Health. Half of them, 50.0\% $(n=76)$ respondents had monthly income from $25000-35000$ taka, $42.7 \%(n=65)$ respondents had monthly income from 15000-25000 taka and 7.3\% (n=11) respondents had monthly income were above35000 taka. Among the respondents, 90.7\% $(n=133)$ respondents were married and $2.6 \%(n=4)$ respondents were unmarried. $61.2 \%(n=93)$ respondents had four to five family members in their family. Most 40.1\% $(n=61)$ respondents lived in their own house. $77.0 \%$ $(\mathrm{n}=141)$ respondents lived in buildings. $16.4 \%(\mathrm{n}=25)$ respondents lived in semi-pacca house. Majority of the respondents $61.2 \%(n=93)$ did not have tobacco consumption habit. 38.8\% $(n=59)$ respondents had tobacco consumption habit. Majority of the respondents 61.8\% ( $n=94)$ had permanent job, 23.7\% ( $n=36)$ respondents had temporary job and $14.5 \%(n=22)$ respondents job were Ad hoc basis job. Majority of the respondents $60.6 \%(n=92)$ were working for above eight years, $23.0 \%(n=35)$ respondents were working for five to eight years and $16.4 \%(n=25)$ up to four years as senior stuff nurse. Of the respondents. $12.5 \%(\mathrm{n}=19)$ respondents had working experience for up to two years. Majority of the respondents $(73.7 \%, n=112)$ had working experience above four years. Most of the respondents $86.2 \%(n=131)$ had national training. Most of the respondents $89.5 \%(n=136)$ did not have international training. Majority of the respondents did not have diabetes mellitus and hypertension.

Table 2 shows the job satisfaction of the respondents. 8.6\% $(\mathrm{n}=13)$ respondents were satisfied with the working environment. 23.0\% $(n=35)$ respondents were dissatisfied with the freedom to choose own work. $22.4 \%(n=34)$ respondents were satisfied with recognition of performance at work. 86.2\% $(n=131)$ respondents were neither satisfactory nor dissatisfactory with cooperation from superior. $18.4 \%(\mathrm{n}=28)$ respondents were satisfied with relation with colleague. $28.9 \%(n=44)$ respondents were dissatisfied with job security. $36.8 \%(n=56)$ respondents were satisfied 
with the salary they got. $64.8 \%(n=104)$ respondents were neither satisfactory nor dissatisfactory with fringe benefit from service. $57.9 \%(\mathrm{n}=88)$ respondents were dissatisfied with promotional scope. $83.6 \%(\mathrm{n}=127)$ respondents were neither satisfactory nor dissatisfactory with work load. 39.5\% $(n=60)$ respondents were satisfied with the place of posting. $16.4 \%(n=25)$ respondents were dissatisfied with opportunity for career advancement.

Table 2 Distribution of the respondents according to job satisfaction $(n=152)$

\begin{tabular}{|l|c|c|c|}
\hline \multicolumn{1}{|c|}{ Job satisfaction } & Satisfactory & $\begin{array}{c}\text { Neither satisfactory } \\
\text { nor dissatisfactory }\end{array}$ & Dissatisfactory \\
\hline Working environment & $13(8.6 \%)$ & $128(84.2 \%)$ & $11(7.2 \%)$ \\
\hline Freedom to choose own work & $20(13.2 \%)$ & $97(63.8 \%)$ & $35(23.0 \%)$ \\
\hline Right position in job & $12(7.9 \%)$ & $113(74.3 \%)$ & $27(17.8 \%)$ \\
\hline Recognition of performance at work & $34(22.4 \%)$ & $83(54.6 \%)$ & $35(23.0 \%)$ \\
\hline Cooperation from superior & $14(9.2 \%)$ & $131(86.2 \%)$ & $7(4.6 \%)$ \\
\hline Relation with colleague & $28(18.4 \%)$ & $120(78.9 \%)$ & $4(2.6 \%)$ \\
\hline Job security & $5(3.3 \%)$ & $103(67.8 \%)$ & $44(28.9 \%)$ \\
\hline Training facility & $13(8.6 \%)$ & $123(80.9 \%)$ & $16(10.5 \%)$ \\
\hline Salary & $56(36.8 \%)$ & $92(60.5 \%)$ & $4(2.6 \%)$ \\
\hline Promotional scope & $1(0.7 \%)$ & $63(41.4 \%)$ & $88(57.9 \%)$ \\
\hline Work load & $9(5.9 \%)$ & $127(83.6 \%)$ & $16(10.5 \%)$ \\
\hline Place of posting & $60(39.5 \%)$ & $88(57.9 \%)$ & $4(2.6 \%)$ \\
\hline Nature of job & $112(73.7 \%)$ & $40(26.3 \%)$ & $0(0.0 \%)$ \\
\hline Opportunity for career advancement & $12(7.9 \%)$ & $115(75.7 \%)$ & $25(16.4 \%)$ \\
\hline
\end{tabular}

Figure 1 shows the level of job satisfaction of the respondents. Majority of the respondents $72.4 \%$ ( $n=110)$ were satisfied with their jobs. $17.8 \%(n=27)$ respondents had poor level of satisfaction regarding their jobs.

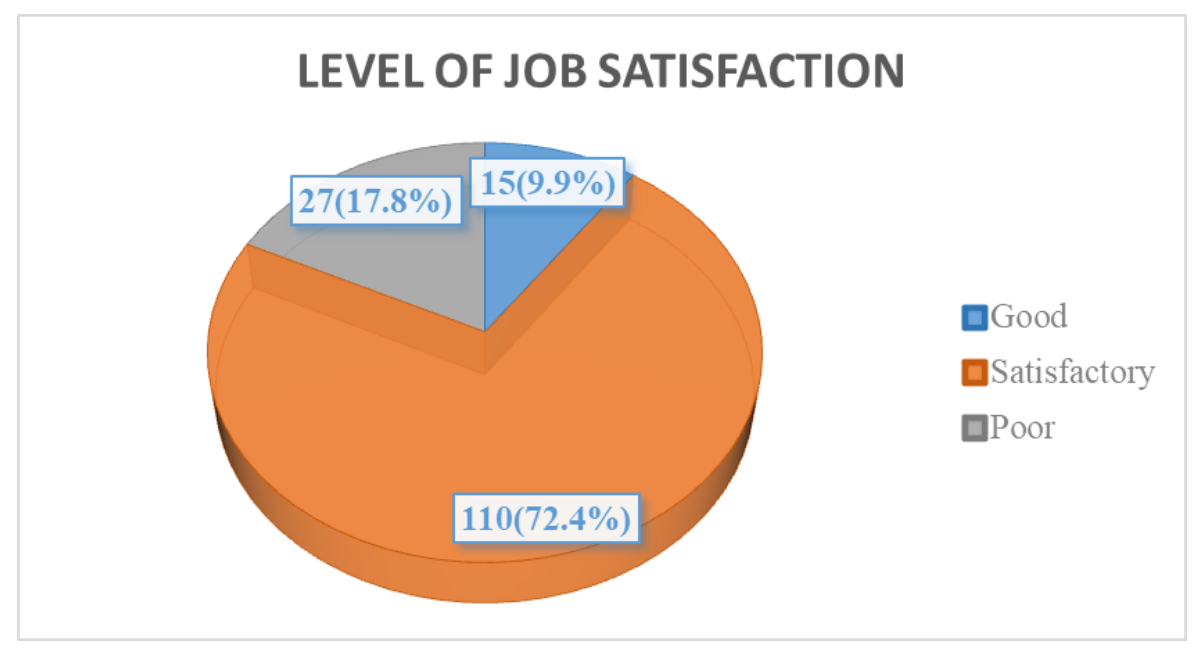

Figure 1 Distribution of level of job satisfaction of the respondents $(n=152)$ 
Table 3 Distribution of the respondents according to factors affects the job satisfaction $(n=152)$

\begin{tabular}{|c|c|c|}
\hline Factors that affect the job satisfaction & Frequency & Percentage \\
\hline \multicolumn{3}{|l|}{ Internal factor } \\
\hline No internal influence & 110 & 72.4 \\
\hline Lack of support from supervisor & 10 & 6.6 \\
\hline Lack of support from colleagues & 7 & 4.5 \\
\hline Lack of adequate equipment & 8 & 5.3 \\
\hline Lack of co-ordination & 3 & 2.0 \\
\hline \multicolumn{3}{|l|}{ External factor } \\
\hline No external influence & 9 & 5.9 \\
\hline Political influence & 78 & 51.3 \\
\hline Religious influence & 23 & 15.1 \\
\hline Communication barrier & 20 & 13.2 \\
\hline Education barrier & 12 & 7.9 \\
\hline Cultural barrier & 10 & 6.6 \\
\hline
\end{tabular}

Table 3 shows the factors that affects the job satisfaction of the respondents. $72.4 \%(n=110)$ respondents said that there were no internal factors that might affect their job satisfaction. 51.3\% $(n=78)$ respondents said that political influence affect their job satisfaction. $13.2 \%(n=20)$ respondents said that communication barrier affect their job satisfaction.

Table 4 Association between level of job satisfaction and socio-demographic status of the respondents $(n=152)$

\begin{tabular}{|c|c|c|c|c|}
\hline $\begin{array}{l}\text { Socio-demographic } \\
\text { variable }\end{array}$ & $\begin{array}{l}\text { Very satisfied } \\
\text { N (\%) }\end{array}$ & $\begin{array}{l}\text { Satisfied } \\
\text { N (\%) }\end{array}$ & $\begin{array}{l}\text { Dissatisfied } \\
\text { N (\%) }\end{array}$ & $P$ value \\
\hline \multicolumn{5}{|l|}{ Age (in years) } \\
\hline $28-37$ & $1(6.7 \%)$ & $21(19.1 \%)$ & $4(14.8 \%)$ & \multirow{3}{*}{$\begin{array}{l}\chi^{2}=15.296^{a} \\
d f=4 \\
p=0.004\end{array}$} \\
\hline $38-47$ & $2(13.3 \%)$ & $57(51.8 \%)$ & $14(51.9 \%)$ & \\
\hline $48-57$ & $12(80.0 \%)$ & $32(29.1 \%)$ & $9(33.3 \%)$ & \\
\hline \multicolumn{5}{|l|}{ Educational status } \\
\hline Diploma passed & $12(80.0 \%)$ & 84(76.4\%) & $14(51.9 \%)$ & \multirow{2}{*}{$\begin{array}{l}\chi^{2}=6.998^{a} \\
d f=2 \\
p=0.030\end{array}$} \\
\hline Above diploma & $3(20.0 \%)$ & $26(23.6 \%)$ & $13(48.1 \%)$ & \\
\hline \multicolumn{5}{|l|}{ Monthly income } \\
\hline Up to 25000 & $2(13.3 \%)$ & $51(46.4 \%)$ & $12(44.4 \%)$ & \multirow{2}{*}{$\begin{array}{l}\chi^{2}=5.922^{a} \\
d f=2 \\
p=0.052\end{array}$} \\
\hline Above 25000 & $13(86.7 \%)$ & $59(53.6 \%)$ & $15(55.6 \%)$ & \\
\hline
\end{tabular}

Table 4 showed the association between socio-demographic variables and level of job satisfaction. Results showed that respondent's age $(\mathrm{p}=0.004)$, educational status $(\mathrm{p}=0.030)$ and monthly family income $(\mathrm{p}=0.052)$ was significantly associated with level of job satisfaction (obtained by Pearson's Chi-square test). 


\section{Discussion}

Employee job satisfaction is the fulfillment, gratification, and enjoyment that come from work. It is not just the money or the fringe benefits, but the feelings employees receive from the work itself. Quality of health care is a multidimensional phenomenon. Job satisfaction among health care providers is a crucial variable among the determinants of quality of health care [13].

The present research had been undertaken with the objective to determine the status of job satisfaction of senior staff nurses working at Upazilla Health Complex. A total of 152 senior staff nurses were selected purposively from 16 Upazilla Health Complexes of five districts of Barisal Division. Data were collected by face-to-face interview. Semi-structured interviewer administered questionnaire was developed to collect the data.

Result of the current study showed that the mean age of the respondents was $44.05 \pm 7.01$ years. Among them, $17.1 \%$ respondents were from 28 to 37 years age group, $48.0 \%$ respondents were from 38 to 47 years age group and $34.9 \%$ respondents were from 48 to 57 years age group. A study was conducted in Turkey where the researchers found that the mean age of the nurses was $31.58 \pm 6.0$ years [14]. The dissimilarity of result might be due to the fact that in the present study, respondents were senior stuff nurses and in the above-mentioned study the respondents were nurses of private hospitals of Turkey.

The study revealed that among the respondents, $90.7 \%(n=148)$ respondents were female and $2.6 \%(n=4)$ respondents were male. This result was consistent with the result of Lorber and Skela Savič, where they found that among the respondents 97.84 respondents were female [15].

Among the respondents, most of the respondents $(n=91,59.9 \%)$ were Muslims. 37.5\% respondents (n=57) were Hindus and $2.6 \%$ respondents $(n=4)$ were Christian. Among them, $30.9 \%(n=47)$ respondents had monthly income from 21000 25000 taka. 20.4\% $(n=31)$ respondents had monthly income from 26000-30000 taka and 29.6\% (n=45) respondents had monthly income from 31000-35000 taka. Among the respondents, $90.7 \%(n=133)$ respondents were married and $2.6 \%(n=4)$ respondents were unmarried. 61.2\% $(n=93)$ respondents had four to five family members in their family. Majority of the respondents $(61.2 \%, n=93)$ did not have tobacco consumption habit. Majority of the respondents did not have diabetes mellitus and hypertension.

The present study found that $72.4 \%(n=110)$ respondents were diploma in nursing, 20.4\% ( $=31)$ respondents were BSc in nursing and 3.3\% $(n=5)$ respondents were Masters in public health. Masum et al. also found that majority of the respondents were diploma passed and only $6.7 \%$ respondents were masters passed [14]. Majority of the respondents $(61.8 \%, n=94)$ had permanent job and $23.7 \%(n=36)$ respondents had temporary job. $14.5 \%(n=22)$ respondents job were Ad hoc basis job.

The study found that $23.0 \%(n=35)$ respondents were working as senior stuff nurse for five to eight years. Majority of the respondents $(60.6 \%, \mathrm{n}=92)$ were working as senior stuff nurse for above eight years. Most of the respondents $(86.2 \%, n=131)$ had national training. Most of the respondents $(89.5 \%, n=136)$ did not have international training. $12.5 \%(n=19)$ respondents had working experience for up to two years. Majority of the respondents $(73.7 \%, n=112)$ had working experience above four years. The result was consistent with the study result conducted in Ethiopia, where the researchers found that $19.4 \%$ respondents had work experience up to two years [16].

There are a variety of factors that can influence a person's level of job satisfaction. Some of these factors include the level of pay and benefits, the perceived fairness of the promotion system within a company, the quality of the working conditions, leadership and social relationships, the job itself (the variety of tasks involved, the interest and challenge the job generates, and the clarity of the job description/requirements) [17]. The job satisfaction level was assessed in the current study with the help of three point Likert scale.

The present study revealed that $8.6 \%(n=13)$ respondents were satisfied with the working environment. But in Turkey, nurses collectively expressed high level of satisfaction with work environment [14]. The dissimilarity of result might be due to the fact that the socio-economic condition of Turkey was higher than Bangladesh. Therefore nurses of Turkey worked in better environment than Bangladesh.

The current study revealed that 57.9\% $(n=88)$ respondents were dissatisfied with promotional scope. Similar result was found by Asegid et al. where they found 41.3\% respondents were dissatisfied with promotional scope [16]. 
The current study revealed that $10.5 \%(n=16)$ respondents were dissatisfied with training facilities. Dissimilar result was found by Asegid et al. [16] where they found 43.8\% respondents were dissatisfied with training facilities. The dissimilarity might be due to the fact that Government of Bangladesh is providing huge trainings to nurses to improve the health care system of Bangladesh. The study found that most of the respondents had professional training so they were not dissatisfied with training facilities.

The current study revealed that $16.4 \%(\mathrm{n}=25)$ respondents were dissatisfied with opportunity for career advancement. Martins et al. found that $19.2 \%$ respondents were dissatisfied with opportunity for career advancement [18].

It was found in the study that $5.9 \%(n=9)$ respondents were satisfied with fringe benefit from service. $28.9 \%(n=44)$ respondents were dissatisfied with job security. $36.8 \%(n=56)$ respondents were satisfied with the salary they got. But in Nigeria it was found that $21.7 \%$ respondents were satisfied with the salary they got. The unmatched result might be due to the low socio-economic background of Nigeria [18].

Present study showed that $23.0 \%(n=35)$ respondents were dissatisfied with the freedom to choice own work. $22.4 \%$ $(\mathrm{n}=34)$ respondents were satisfied with recognition of performance at work. $86.2 \%(\mathrm{n}=131)$ respondents were neither satisfactory nor dissatisfactory with cooperation from superior. $18.4 \%(n=28)$ respondents were satisfied with relation with colleague. $83.6 \%(n=127)$ respondents were neither satisfactory nor dissatisfactory with work load. $39.5 \%$ (n=60) respondents were satisfied with the place of posting.

The level of job satisfaction of the respondents was assessed in the present study. It was found that majority of the respondents $(72.4 \%, n=110)$ were satisfied with their jobs. $17.8 \%(n=27)$ respondents had poor satisfaction level regarding their jobs. Martins et al. found that 57.5\% respondents were satisfied with their jobs and 23.5\% respondents were dissatisfied with their jobs (Martins et al., 2016). The possible explanation of the dissimilarity might be due to the low socio-economic background of Nigeria. As Bangladesh is in higher position regarding socio-economic class compared to Nigeria, nurses of were more satisfied than Nigeria. Results showed that respondent's age ( $p=0.004$ ), educational status $(\mathrm{p}=0.030)$ and monthly family income $(\mathrm{p}=0.052)$ was significantly associated with level of job satisfaction. Lorber and Skela Savič also found that respondent's age was significantly associated with level of job satisfaction [15].

There are several factors which affects the job satisfaction of the respondents. $72.4 \%(\mathrm{n}=110)$ respondents said that there were no internal factors that might affect their job satisfaction. $51.3 \%(n=78)$ respondents said that political influence affect their job satisfaction. $13.2 \%(n=20)$ respondents said that communication barrier affect their job satisfaction.

\section{Conclusion}

Job satisfaction is a noteworthy issue for ensuring proper nursing care in healthcare sector. Furthermore, job satisfactions of nurses will ensure better quality healthcare services and enhance their professional commitment. The present study was conducted with the objective to determine the status of job satisfaction of senior staff nurses working at Upazilla Health Complex. Majority of the respondents were satisfied with their jobs. Nurse's age, educational status and monthly family income was significantly associated with level of job satisfaction. Political influence and communication barrier affect their job satisfaction. Special attention should be given for their promotional opportunity to increase their level of job satisfaction.

\section{Recommendations}

Based on the findings of the study, the following recommendations can be made in order to improve the job satisfaction of senior staff nurses in Upazila Health Complexes that will ultimately lead to improvement of quality care to the patient

- Influences at work place either internal or external should be removed to ensure effective patient care.

- Develop career ladder for the nursing profession

- Special attention required to the promotional opportunity of senior staff nurses according to educational qualification and service experience.

- Recognition giving for good work to encouraging nursing staff.

- Public awareness should be grow for job evaluation of nurses as Nobel Profession. 


\section{Compliance with ethical standards}

\section{Acknowledgments}

I express gratitude's to my respected teacher and guide Dr. Kazi Jahangir Hossain PhD. Program Co-ordinator, MPH Program, NIPSOM, Professor (Dr) BaizidKhoorshidRiaz, Director of National Institute of Preventive \& Social Medicine (NIPSOM), Dr.A M N Shamsul Islam Associate Professor, Department of public health and Hospital Administration, Course in charge, Hospital Management, for their expert supervision, continuous support and suggestion during entire period of the study. My hearty thanks go to the authority of Selected Upazila Health Complexes in Barisal Division for the kind permission to conduct may research at their health complex and my heartfelt thanks to the entire respondent for being compliant to my request for providing necessary information as per questionnaire.

\section{Disclosure of conflict of interest}

None to declare.

\section{Statement of informed consent}

Informed consent was obtained from all individual participants included in the study.

\section{References}

[1] Munyewende PO, Rispel LC, Chirwa T. Positive practice environments influence job satisfaction of primary health care clinic nursing managers in two South African provinces. Human resources for health. 2014 Dec; 12(1): 1-4.

[2] Kinzl JF, Knotzer H, Traweger C, Lederer W, Heidegger T, Benzer A. Influence of working conditions on job satisfaction in anaesthetists. British Journal of Anaesthesia. 2005 Feb 1; 94(2): 211-5.

[3] Sutherland VJ, Cooper CL. Job stress, satisfaction, and mental health among general practitioners before and after introduction of new contract. British Medical Journal. 1992 Jun 13; 304(6841): 1545-8.

[4] Kumar R, Ahmed J, Shaikh BT, Hafeez R, Hafeez A. Job satisfaction among public health professionals working in public sector: a cross sectional study from Pakistan. Human resources for health. 2013 Dec; 11(1): 1-5.

[5] Lambert EG, Hogan NL, Barton SM. The impact of job satisfaction on turnover intent: a test of a structural measurement model using a national sample of workers. The Social Science Journal. 2001 Jun 1; 38(2): 233-50.

[6] Ning S, Zhong H, Libo W, Qiujie L. The impact of nurse empowerment on job satisfaction. Journal of advanced nursing. 2009 Dec; 65(12): 2642-8.

[7] Pietersen C. Job satisfaction of hospital nursing staff. SA Journal of Human Resource Management. 1 Jan 2005; $3(2): 19-25$.

[8] Hadley MB, Roques A. Nursing in Bangladesh: rhetoric and reality. Social science \& medicine. 1 Mar 2007; 64(6): 1153-65.

[9] Laschinger HK. Effect of empowerment on professional practice environments, work satisfaction, and patient care quality: Further testing the nursing worklife model. Journal of nursing care quality. 1 Oct 2008; 23(4): 32230.

[10] Whitman DS, Van Rooy DL, Viswesvaran C. Satisfaction, citizenship behaviors, and performance in work units: A meta-analysis of collective construct relations. Personnel psychology. 2010 Mar; 63(1): 41-81.

[11] Seago JA, Spetz J, Ash M, Herrera CN, Keane D. Hospital RN job satisfaction and nurse unions. JONA: The Journal of Nursing Administration. 2011 Mar 1; 41(3): 109-14.

[12] Tovey EJ, Adams AE. The changing nature of nurses' job satisfaction: an exploration of sources of satisfaction in the 1990s. Journal of advanced nursing. 1999 Jul; 30(1): 150-8.

[13] Al Otabi M, Shah MA, Chowdhury RI, Al-Enezi N. Determinants of job satisfaction among nurses in Kuwait. Australian Journal of Advanced Nursing, The. Jun 2004; 21(4): 10.

[14] Masum AK, Azad MA, Hoque KE, Beh LS, Wanke P, Arslan Ö. Job satisfaction and intention to quit: an empirical analysis of nurses in Turkey. PeerJ. 26 Apr 2016; 4: e1896. 
[15] Lorber M, Skela Savič B. Job satisfaction of nurses and identifying factors of job satisfaction in Slovenian Hospitals. Croatian medical journal. 15 Jun 2012; 53(3): 263-70.

[16] Asegid A, Belachew T, Yimam E. Factors influencing job satisfaction and anticipated turnover among nurses in Sidama zone public health facilities, South Ethiopia. Nursing research and practice. 24 Feb 2014.

[17] Parvin MM, Kabir MN. Factors affecting employee job satisfaction of pharmaceutical sector. Australian journal of business and management research. 1 Dec 2011; 1(9): 113.

[18] Martins OF, Tukur D, Danburam A, Salwau FK. Job satisfaction among doctors and nurses: a case study of federal medical centre Yola, Nigeria. International Journal of Community Medical Public Health. Jun 2016; 3(6): 1640-7. 